\title{
Use Ordinary Expressions to Learn How to Extract Code Feedback from the Software Program Upkeep Process
}

\author{
Anggara Trisna Nugraha, Muhammad Jafar Shiddiq, Moch Fadhil Ramadhan \\ Marine Electrical Engineering Shipbuilding Institute of Polytechnic Surabaya, Jl. Teknik Kimia Keputih Sukolilo, \\ Surabaya 60111, Indonesia \\ Automation Engineering Shipbuilding Institute of Polytechnic Surabaya, Jl. Teknik Kimia Keputih Sukolilo, Surabaya \\ 60111, Indonesia
}

\begin{tabular}{l} 
Article Info \\
\hline Article history: \\
Received Apr 02, 2021 \\
Revised Oct 09, 2021 \\
Accepted Oct 30, 2021 \\
\hline
\end{tabular}

\section{Keywords:}

Regular expression Software maintenance

Slicing

Pourcecode

Program understanding

\begin{abstract}
Software engineering is the manner of making use of engineering studies and alertness packages to the design, improvement and renovation of software program. For software program builders or college students majoring in data engineering, the software program renovation manner is a totally complicated activity. Software renovation manner charges account for $40 \%$ to $80 \%$ of the whole software program engineering manner. The software program renovation manner is resulting from based programming, inadequate understanding domains, and application documentation. In this study, researchers attempted to apply the Java programming language and $\mathrm{c} / \mathrm{c}++$ to deal with supply code truncation. After finishing this manner, this system code may be divided into code and remarks. This report could be used to gain data approximately the manner of knowledge this system from the software program renovation manner. For supply code slicing, the writer makes use of normal expressions, specifically textual content processing strategies or patterns. Using normal expressions can accelerate the manner of locating remarks to your application. The end result of this studies is to construct an software primarily based totally on open supply code (loose license) so that scholars and trendy programmers can use it to assist apprehend this system. According to the effects of the researchers' testing, the recuperation price is $100 \%$ and the accuracy is $100 \%$.
\end{abstract}

This is an open access article under the CC BY-SA license.

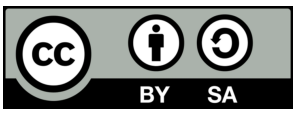

\section{Corresponding Author:}

Anggara Trisna Nugraha,

Marine Electrical Engineering,

Shipbuilding Institure of Polytechnic Surabaya,

J1. Teknik Kimia Keputih Sukolilo, Surabaya 60111, Indonesia.

Email: anggaranugraha@ppns.ac.id

\section{INTRODUCTION}

To be capable of write excellent packages, college students of the Informatics Engineering Department can perform in ways, particularly studying books associated with programming and turning easy packages into very complicated packages. To create a software program, university college students can take ways, especially growing their very personal software program or downloading programs from an individual's website. The method of downloading programs from the Internet requires the cappotential to take look at programs and understand one-of-a-kind programs.

Software engineering is an interest that consists of developing, designing, and keeping software program application that focuses on improving the amazing of programs or software 
program application which may be built. In addition, via way of means of wearing out those software program engineering sports, builders or college students may be capable of hit upon mistakes that arise withinside the software program. Therefore, the procedure of know-how a software is a completely critical procedure in software program engineering [1].

One of the most critical elements in software retention is the software know-how process. When manufacturers engage in storage, software reuse, software migration procedures, remodel and improve of software program systems, they want to apprehend the software. In this regard, many research were performed to offer steerage and guide for the software program improvement procedure [2]. Program know-how sports are carefully associated with software program preservation. Understanding software sports in software program preservation calls for extra than $50 \%$ of the programmer's overall performance and debts for $40 \%$ to $80 \%$ of all software program preservation sports. The procedure of know-how a software that calls for an overall performance of extra than $50 \%$ is as a result of many factors, certainly considered one among that is programming achieved via way of means of many programmers, that could result in distinct understandings of a given task [3].

Regular expressions are symbols used to explain styles of textual content (operations on textual content); Regular expressions are utiliz in current programming languages, inclusive of PHP, Java, and Python. Regular expressions are used to get positive sentence styles for precise purposes [4]. In this study, the researchers used daily expressions to obtain the observations contained in the software.

Based on the heritage above, the researchers followed the research theme on the preservation of software. In particular, the general public can study current plans through free licenses.

\subsection{The Aim of the Research}

The aim of this research is:

- Retrieve open-source program annotation information about the software maintenance process.

- Use regular expressions to find program comments during search.

- To examine whether by default applications can run in memory and what percentage of default applications in memory can fit.

\subsection{Software engineering}

Computers are divided into primary layers: hardware and software program [5], and the hardware itself is split into 3 parts, specifically bodily devices, micro programming, and device language [6]. Software is split into parts: gadget packages and alertness packages. System packages are software program that control the gadget itself and manage different hardware and offer area to run present software packages [6]. Applications are packages constructed to clear up person problems [7] [8] [9].

Software engineering is a field of expertise that explores how to create, develop, contain and control the beauty of software packages. According to the IEEE Computer Society, software engineering is the software generation with a scientific and disciplined method for the software program being created.

In general, the definition of software program engineering application is the software of many software program development concepts. Software engineering is utilized in making programs which might be extra complicated and large, normally utilized in growing software program packages for the desires of businesses, corporations and large-scale companies.

\section{Elements of Software Engineering}

In the process, the software engineering program has three important elements that are the keys to success, namely:

1. Method

The first element is a method, there are several series of tasks that must be done such as:

- Project planning and estimation process

International Journal of Advances in Data and Information Systems, Vol. 2, No. 2, October 2021 : 105-113 
- Analysis of program and system software requirements

- Designing a statistical structure

- Software architecture to be created

- Algorithm procedure used

- Coding software

- Software testing

- Software maintenance

2. Equipment

The tools of the software engineering program are intend to provide support for the methods, for example:

- CASE is a software program that has the function of combining software programs, hardware and database software engineering programs to produce good engineering software programs.

- Database software engineering program is a statistical structure, which contains important information about software analysis, software design, software code and trying out software.

- CAD (Computer Aided Design)

- CAE (Computer Aided Engineering)

- CAM (Computer Aided Manufacturing)

3. Procedure

The software engineering program consists of:

- The sorting method used

- Documents, forms and reports required

- Program software quality control

- Coordinating changes in program software

In the development process, software engineering has two roles, namely as a product and as a process. As a product, software engineering plays a role in what products will be developed. As a process, software engineering is a method that must obtain the desired result (software product).

Software is not like hardware, due to time, dust and usage, the hardware will suffer damage or degradation in performance. Software has very different characteristics from hardware, namely [10]:

a. Unlike mass-produced hardware, software is a development or engineering activity.

b. Software will never go out of style, and the longer the hardware, the bigger the drop in performance.

c. Some of the software is develope based on industry orders.

Look at Figure 1 which explains the characteristics of the 2 graphs that distinguish between hardware usage characteristics and Software usage characteristics.

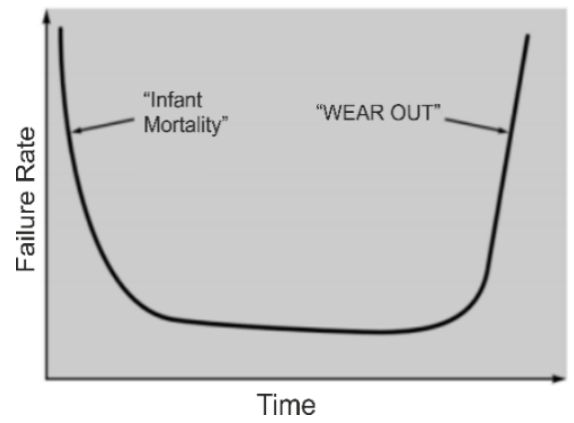

(A)

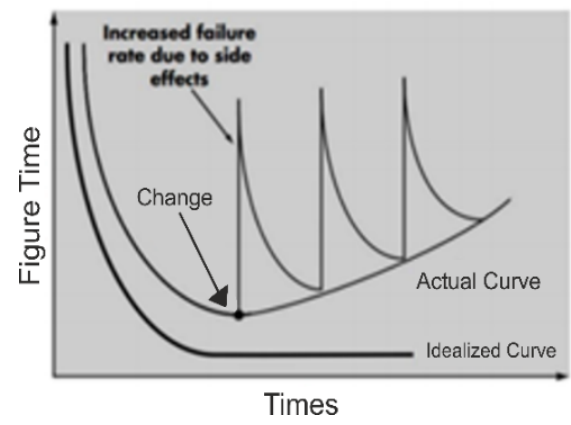

(B)

Figure 1. Characteristics of Hardware (A) and Software (B) 


\subsection{Information Retrieval System}

Toffler writes in his ee-e book that a key thing of the twenty first century is "statistics", wherein power, power, wealth and impact depend upon the ownership of statistics. The fast glide of statistics waves is followed via way of means of the effect of fast technological changes. On the other hand, humans want extensive experience without being the limited by clothing statistics, empirical science, and sensible technology. Therefore, it is able to decid that handiest people or agencies who have the statistics can acquire success [10].

If a pc is ready with a statistics retrieval gadget, the statistics saved in a set of files may be accessed through the pc. The statistics retrieval gadget is chargeable for coping issues with selecting items in a report collection. These items are statistics that can be of hobby to users, which may be textual content files, items in museums, or different styles of statistics that can be accrued withinside the future. [11].

ISO 2382/1 defines Information Retrieval (IR) as the subsequent operations, techniques and processes: convalescing saved records after which imparting the essential statistics approximately the subject. These steps encompass textual content indexing, question analysis, and correlation analysis. Data consists of textual content, tables, images, sound and video, and statistics consists of applicable expertise to help hassle fixing and expertise acquisition [12].

Classic modes in statistic retrieval structures are divided into 3 types: Boolean modes, vector area modes and opportunity modes. The Boolean version is the best version. The version is primarily base totally on set idea and Boolean algebra. The vector area version is a version that represents files and queries withinside the shape of dimensional vectors, whilst the opportunity version is a version that makes use of an opportunity framework [13] [14].

\subsection{Program Understanding}

Understanding laptop programming is one of the intermediate sports of software engineering. Developers want to learn the procedures involved in retaining, reusing, migrating, redesigning, or upgrading software systems. Therefore, a number of studies on software expertise has been done, that is a guiding principle and help for software program engineers [2].

In early 1968, the North Atlantic Treaty Organization (NATO) introduced the advent of the primary software program engineering seminar, which posed a mission to expertise the plan. Since then, software expertise studies have been one of the maximum advanced regions of studies. The aim of a network expertise plan is to construct an expertise of the plan through growing greater powerful equipment and techniques. Program expertise studies has primary objectives, one is to try to understand the empirical observation of the cognitive procedures used by programmers to learn the programs, and the opposite is to cognizance studies strategies on semi-automated improvement equipment to enhance software expertise. Program [15].

Some of the techniques that may be used to apprehend this system are top-down expertise, bottom-up expertise and complete expertise. Top-down expertise is the system of acquiring and refining assumptions approximately plan objectives. Regardless of the (provisional) information of this system, the developer first makes (conclusions) popular assumptions approximately this system objectives. In this step, beacons (for example, a part of the supply code that represents a selected occasion withinside the shape of a) shape or operation) is used to assist decide software objectives. After filing a speculation, the developer will use distinguishing facts to assess it and refine the speculation by formulating and refining sub-assumptions so that a "top-down" method can be used to decide the goals of the plan. The bottom-up definition describes how to learn software when the programmer is no longer learning the dominant software domain. In this case, the programmer will observe the declarations (declarations) of this system and put them in understandable parts. Comprehensive expertise is a technical version that mixes top-down expertise and bottom-up expertise. Top-down expertise permits the developer to give an explanation for the purpose of the prevailing software and is taken into consideration greater efficient [16]. 


\subsection{Software Maintenance}

System renovation is a trendy time period required for the ordinary operation of a gadget, which may be a pc gadget, a mechanical gadget, or another gadget. System renovation is associated with gadget screw ups as a result of customers and age. The renovation surroundings do now no longer practice to software program that looks because of unreasonable utilization and intervals of use. Usually, software program renovation is involved with enhancing the software program gadget. Compared to the previous improvement of new utilities, compared to the new improvement of utilities, software improvement organizations want to spend some time in software renewal. As we all know, software program renovation fees attain $40 \%-70 \%$ of the full employer fees [17].

Software renovation is the maximum vital interest in software program engineering, for extra than ten years, the employer's software program renovation fees have endured to increase. The software environment and its needs are constantly changing, mainly due to software updates [18]. From the studies that has been done, software program renovation sports are at once associated with knowledge software program. Research associated with software program renovation consists of data retrieval, idea mapping, and software program knowledge. The definition of software program may be described as a programming manner or interest associated with current programming know-how and software data, and may be redefined in a extra dynamic or static shape (which may be carried out in a smaller shape (task). The understanding of this system is closely associated with the cognitive potential of the programmer for the software [19].

Because of the excessive fee of knowledge packages, re-documenting is the important thing to software program renovation. Software managers' knowledge of software program structures could be very vital to software program improvement itself, however the contributors concerned in keeping the software program itself are normally now no longer them. Who makes the software program. Apply from scratch. Managers do now no longer have the cappotential to keep software program, so it'll have an effect on the effectiveness and performance of software program renovation. The modern-day answer furnished is to rewrite this system code on the software stage or layout stage, now no longer on the area stage [20].

Comments are the interface among herbal language and supply code. A key part of software program engineering those programmers and maintainers use to help recognize and maintain packages is provisioning code feedback. Source code feedback can also be used as a procurement code quality score. The most effective file shape on this software. Comments covered in the software will help software customers to recognize the reason for this system or current sections of the software. In order for the supply code to be readable, it must specify the meaning of the code. In this case, the effect of the annotated and easy to review provisioning code is software quality, software stability, software knowledge, software renewal, software improvement, software code reuse, software redesign and improved software generation [21].

\section{RESEARCH METHOD}

Software is different from hardware. When we use a hardware component, we have to pay or try to perform maintenance because it is outdated or some devices are damaged. Software isn't like that, it won't be outdated or damaged. However, he will always change after the first version is finished. Well, that's called protection in software.

There are four types of protection in software:

- Corrective protection, we do this when a worm is found in the system and we have to make repairs.

- Adaptive protection, when the system we are building has to adapt to changes in the environment in which the system operates. For example, when creating an Android app, we need to provide protection while updating the Android version, so that our app remains compatible.Perfective protection, when system users or stakeholders change the requirements of the system we are building.

- Preventive protection, when we want to improve the quality of the system we are building or want to treat a worm before it happens. 

2 below:

In this study, the methodology used to achieve the research objectives can be seen in Figure

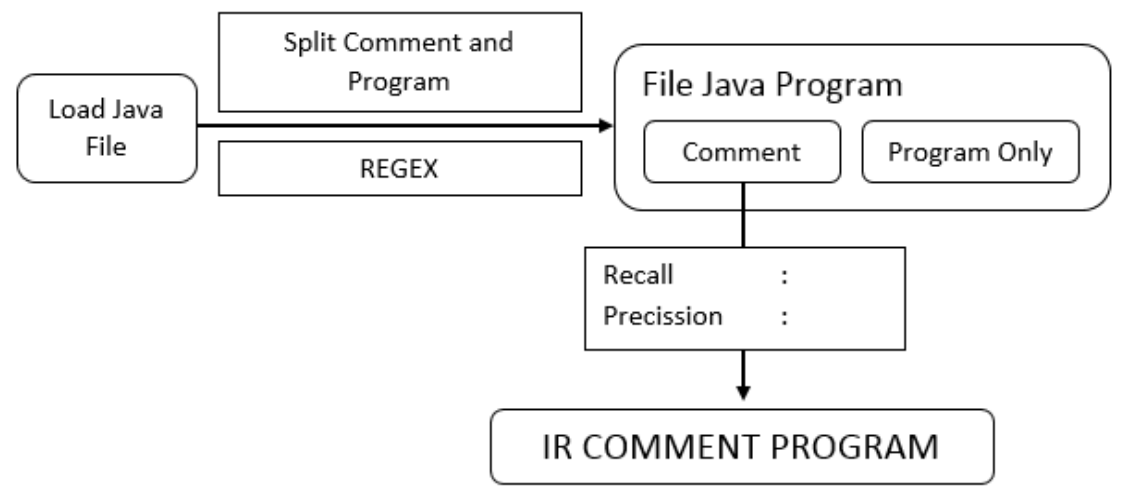

Figure 2. Research methodology

As shown in Figure 2 above, the first thing to do is the * java * file. A Java program consists of two main parts: the program description and the program itself. Comments: To use a regular expression (REGEX) to provide comments to program researchers, program comments have two forms, namely single comments and compound comments. Comments in the Java programming language are marked with a "\#" followed by the comment to be given, while compound comments start with "/ *" and end with "*/".

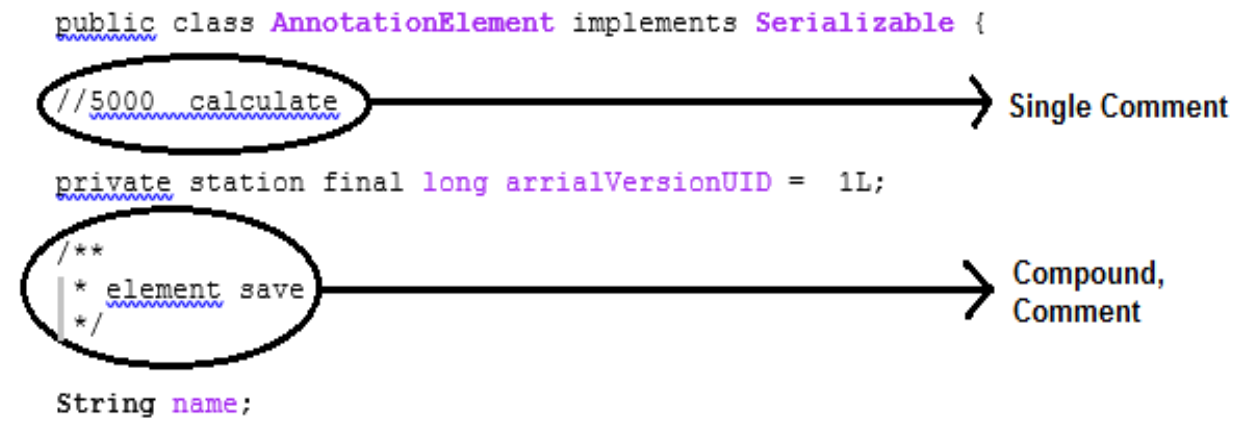

Figure 3. Single and Compound Comments on Java

Figure 3 explains Java programming in order to be able to distinguish between the 2 comment functions, namely the "single comment" and "Compound comment" functions. Then REGEX is used to detect single comments and compound comments and blank lines, as shown in the following table:

Table 1. REGEX Detection of comments and blank lines

\begin{tabular}{|c|c|}
\hline No & Detcetion Comment \\
\hline 1 & $\begin{array}{l}\text { String regex_comments }= \\
" \wedge / 1^{*}\left(?>\left(?:\left(?>\left[{ }^{\wedge *}\right]+\right) \mid \| *(? ! /)\right)^{*}\right) \| * / \mid\left(/ / *^{*}\right)^{\prime \prime}\end{array}$ \\
\hline 2 & String regex_comments $2=" \wedge{ }^{*}||{ }^{*} \backslash \mathrm{V} /\left|\|^{*}\right| / / "$; \\
\hline 3 & String regex_empty_ln $=" \wedge \| s * \$$ \\
\hline
\end{tabular}

To get the level of accuracy and performance carried out according to the needs of this study, it can be used as a reference in Figure 3 to get the value of the level of accuracy. 
Table 2. The formula for getting Recall and Precision

\begin{tabular}{|c|c|c|c|}
\hline \multicolumn{2}{|c|}{} & \multicolumn{2}{c|}{ True Vaule } \\
\cline { 3 - 4 } \multirow{4}{*}{$\begin{array}{c}\text { Predictive } \\
\text { Value }\end{array}$} & TRUE & $\begin{array}{c}\text { TRUE } \\
\text { (TP } \\
\text { Corect result }\end{array}$ & $\begin{array}{c}\text { FALSE } \\
\text { (False Postitive) } \\
\text { Unexpected Result }\end{array}$ \\
\cline { 2 - 4 } & FALSE & $\begin{array}{c}\text { FN } \\
\text { (False Negative) } \\
\text { Missing Result }\end{array}$ & $\begin{array}{c}\text { TN } \\
\text { (True Negative) } \\
\text { Corect avsence of result }\end{array}$ \\
\hline
\end{tabular}

Based on the formula in table 2. To determine the appropriate value and can determine the level of precision of the specified value. Then you can do calculations according to the formula that has been determined:

$$
\text { Precision }=\frac{T P}{T P+F P}
$$

To determine the recall value restriction, it can be in accordance with the following formula:

$$
\text { Recall }=\frac{T P}{T P+F N}
$$

To determine the appropriate accuracy value, it can be calculated using the following formula:

$$
\text { Accuracy }=\frac{T P+T N}{T P+T N+F P+F N}
$$

\section{RESULTS AND DISCUSSION}

The annotation information extraction process has not been completed. Judging from the results of the experiments that have been carried out, the application built by the researcher has been able to separate annotations, processes, and get $100 \%$ performance and accuracy results.

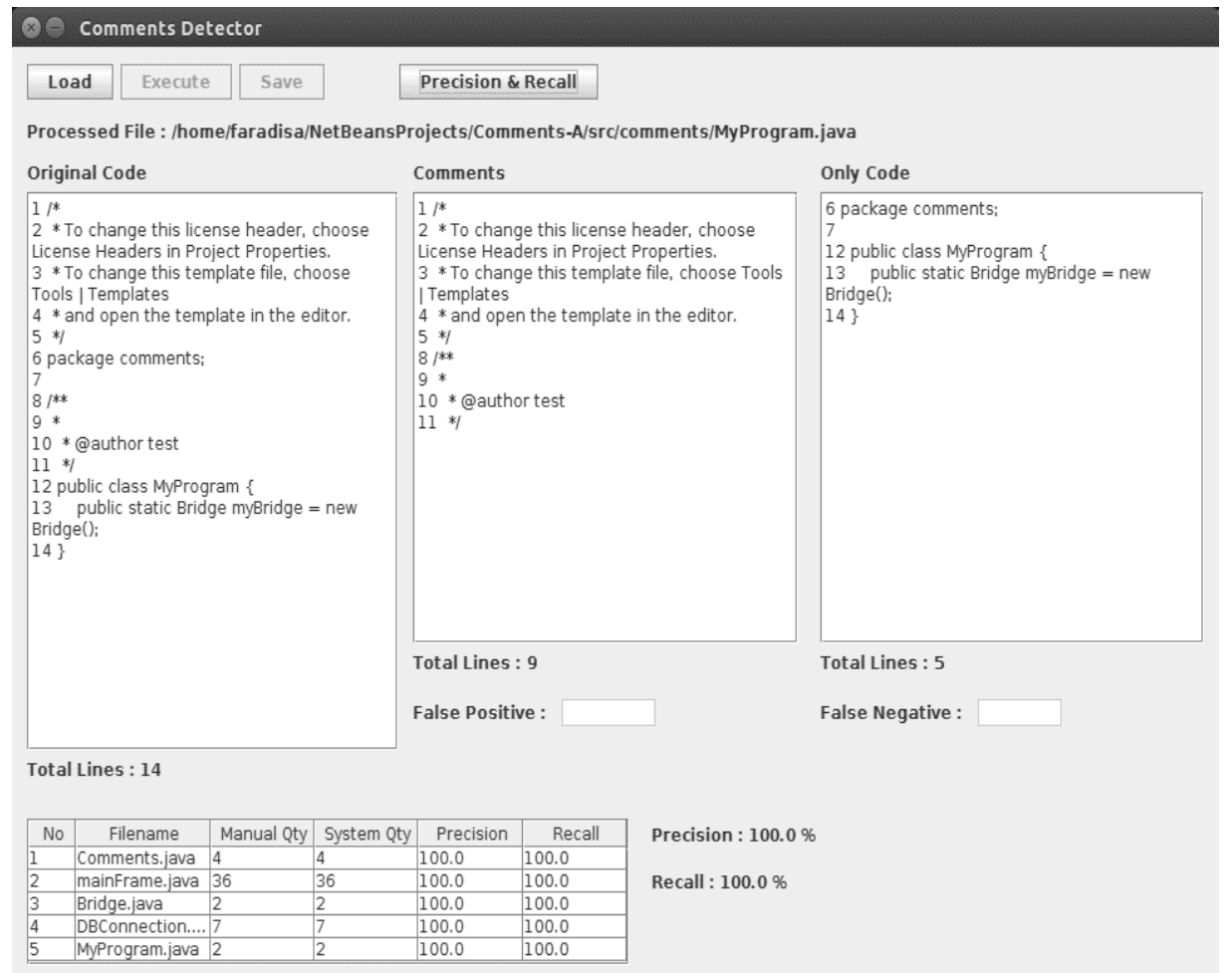

Figure 4. Extraction of program comment information complete with recall and precission. 


\section{CONCLUSION}

Based at the consequences of the studies that has been completed, the subsequent conclusions may be drawn:

1. REGEX could be very good, and appropriate for textual content manipulation, due to the fact it's far used to stumble on application feedback and this system itself.

2. The built-in app may stumble upon memories and adapt $100 \%$ correctly.

3. The most efficient default utility detects annotations and cannot provide annotation responses for this system.

4. Creation of this research by using regular expressions to find programming comments during research.

5. The research methodology reports several important points that can be used as a reference for research "Expressions to Learn How to Extract Code Feedback from the Software Program Upkeep Process".

\section{REFERENCES}

[1] Amandeep Kaur and Balraj Singh, 2014, Study on Metrics Based Approach for Detection Software Code Clones, International Journal of Advanced Research in Computer Science and Software Engineering, Volume 4, Issue 1, pp. 601 - 603.

[2] Michael P. O'Brien, 2003, Software Comprehension - A Review \& Research Direction, Technical Report UL-CSIS-03-3.

[3] Nugraha, Anggara Trisna, and Dadang Priyambodo. "Design of a Monitoring System for Hydroganics based on Arduino Uno R3 to Realize Sustainable Development Goals number 2 Zero Hunger." Journal of Electronics, Electromedical Engineering, and Medical Informatics 3.1 (2021): 50-56.

[4] R. Babi Saraswathi, K. Divya, A. Habeebur Rahman, D.B. Hari Prakash, S. Jayanth, T. Kumar, and S. Mohan Kumar, 2014, System of Quality Automation for Documents (SQAD), International Journal of innovative Research in Computer and Communication Engineering, Vol.2, Issue 1.

[5] Jibitesh Misrah and Ashok Mohanty, 2011, Software Engineering, Pearson Education, pp. 2.

[6] Andrew S. Tanenbaum, 2001, Modern Operating System Second Edition, Pearson Education, pp. 2-3.

[7] Nugraha, Anggara Trisna, and Dadang Priyambodo. "Development of Rocket Telemetry in Chamber Gas Pressure Monitoring with the MPXV7002DP Gas Pressure Sensor." Journal of Electronics, Electromedical Engineering, and Medical Informatics 2.3 (2020): 103-107.

[8] Nugraha, Anggara Trisna, and Dadang Priyambodo. "Analysis of Determining Target Accuracy of Rocket Launchers on Xbee-Pro based Wheeled Robots to Realize the Development of Technology on the Military Field." Journal of Electronics, Electromedical Engineering, and Medical Informatics 2.3 (2020): 114-118.

[9] Marziah Karch, 2014, Apps, http://google.about.com/od/a/g/apps_def.htm

[10] A. Toffler, 1970, Future Shock, Pan Books Ltd.

[11] Nugraha, Anggara Trisna. "Desain Kontrol Output Feedback dengan Command Generator Tracker Berbasis LOS Pada Jalur Lingkaran Menggunakan Quadcopter." Jurnal Teknologi Elektro 9.2 (2018): 73-78.

[12] Yahma Wisnani, 2004, Queri Ganda Pada Sistem Temu Kembali Informasi Berbasis Jaringan Inferensi, MAKARA SAINS, Vol.8 No.2, pp. 76-84.

[13] Juan Bernabe Moreno, 2004, Information Retrieval Meets Semantic Web, Content Management and Information Retrieval Converging.

[14] Angga, Anggara Trisna Nugraha, et al. "Solutions For Growing the Power Factor Prevent A Reactive Electricity Tariff And Decrease Warmth On Installation With Bank Capacitors." Applied Technology and Computing Science Journal 4.1 (2021): 35-46.

[15] Nugraha, Anggara Trisna, and Rahman Arifuddin. "Gas Pressure Measurement On Rocket Chamber Based On Strain Gauge Sensor." JEEMECS (Journal of Electrical Engineering, Mechatronic and Computer Science) 3.2 (2020): 165-170.

[16] Janet Feigenspan, 2011, Program Comprehension of Feature-Oriented Software Development, International Conference on Software Engineering.

[17] Nugraha, Anggara Trisna, and Dadang Priyambodo. "Analysis of Determining Target Accuracy of Rocket Launchers on Xbee-Pro based Wheeled Robots to Realize the Development of Technology on the Military Field." Journal of Electronics, Electromedical Engineering, and Medical Informatics 2.3 (2020): 114-118. 
[18] Sheo Kumar, Sugandha Chakraverti, S.C. Agarwal and Ashish Kumar Chakraverti, 2012, Modified COCOMO Model for Maintenance Cost Estimation of Real Time System Software, International Journal of Research In Engineering \& Applied Sciences, Volume 2, Issue 3.

[19] Tara Kelly and Jim Buckley, 2009, Cognitive Levels and Software Maintenance Sub-Tasks, PPIG Limerick.

[20] Nugraha, Anggara Trisna, and Rahman Arifuddin. "O2 Gas Generating Prototype In Public Transportation." JEEMECS (Journal of Electrical Engineering, Mechatronic and Computer Science) 3.2 (2020): 187-192.

[21] Manjot Signh Ahuja, Surender Dhaiya and Neha Sadana, 2014, A Metric Mased Approach to Measure the Quality of Inline Comments in Source Code, International Journal of Computer Application, Volumen 1, Issue 4. 